\title{
Characteristics of Arctic low-tropospheric humidity inversions based on radio soundings
}

\author{
T. Nygård ${ }^{1}$, T. Valkonen ${ }^{1,2}$, and T. Vihma ${ }^{1}$ \\ ${ }^{1}$ Finnish Meteorological Institute, Helsinki, Finland \\ ${ }^{2}$ Norwegian Meteorological Institute, Oslo, Norway \\ Correspondence to: T. Vihma (timo.vihma@fmi.fi)
}

Received: 13 August 2013 - Published in Atmos. Chem. Phys. Discuss.: 29 August 2013

Revised: 10 January 2014 - Accepted: 17 January 2014 - Published: 20 February 2014

\begin{abstract}
Humidity inversions have a high potential importance in the Arctic climate system, especially for cloud formation and maintenance, in wide spatial and temporal scales. Here we investigate the climatology and characteristics of humidity inversions in the Arctic, including their spatial and temporal variability, sensitivity to the methodology applied and differences from the Antarctic humidity inversions. The study is based on data of the Integrated Global Radiosonde Archive (IGRA) from 36 Arctic stations between the years 2000 and 2009. The results indicate that humidity inversions are present on multiple levels nearly all the time in the Arctic atmosphere. Almost half (48\%) of the humidity inversions were found at least partly within the same vertical layer with temperature inversions, whereas the existence of the other half may, at least partly, be linked to uneven vertical distribution of horizontal moisture transport. A high atmospheric surface pressure was found to increase the humidity inversion occurrence, whereas relationships between humidity inversion properties and cloud cover were generally relatively weak, although for some inversion properties they were systematic. For example, humidity inversions occurred slightly more often and were deeper under clear sky than in overcast conditions for almost all stations. The statistics of Arctic humidity inversion properties, especially inversion strength, depth and base height, proved to be very sensitive to the instruments and methodology applied. For example, the median strength of the strongest inversion in a profile was twice as large as the median of all Arctic inversions. The most striking difference between the Arctic and Antarctic humidity inversions was the much larger range of the seasonal cycle of inversion properties in the Arctic. Our results offer a baseline for validation of weather prediction and climate models and
\end{abstract}

also encourage further studies on humidity inversions due to the vital, but so far poorly understood, role of humidity inversions in Arctic cloud processes.

\section{Introduction}

Atmospheric water vapour has major impacts on the Earth's surface energy balance through radiative fluxes and cloud formation. The amount of water vapour typically decreases with height, but in polar regions, layers with the amount of water vapour increasing with height have been found to be very common and simultaneously occur on multiple levels (Devasthale et al., 2011; Vihma et al., 2011; Kilpeläinen et al., 2012; Nygård et al., 2013). These humidity inversions have many important implications for cloud growth and persistence in the Arctic. They often occur near the cloud top, coincident with temperature inversions, providing a moisture source to the cloud layer through entrainment (Solomon et al., 2011; Sedlar et al., 2012; Tjernström et al., 2012). If the cloud layer is decoupled from the surface, humidity inversions can even be the only moisture source to the layer (Solomon et al., 2011). Devasthale et al. (2011) stated that humidity inversions contribute to keeping the Arctic cloud cover extensive, which implies that humidity inversions extend to large spatial scale. In addition to implications for clouds, humidity inversions also notably influence longwave radiation characteristics in clear-sky conditions (Devasthale et al., 2011).

Nygård et al. (2013) summarized that humidity inversions in the Antarctic coastal zone are formed and supported by condensation, horizontal advection of water vapour, 
turbulence and large-scale vertical motions. Condensation, which is related to the temperature control of saturation pressure, is therefore also linked to the presence of temperature inversions (Wetzel and Brümmer, 2011; Sedlar et al., 2012; Tjernström et al., 2012; Nygård et al., 2013). Devasthale et al. (2011) found a clear nonlinear relationship between humidity and temperature inversion strength in all seasons except during summer in the Arctic. Similarly, Nygård et al. (2013) found a connection between humidity and temperature inversion strength, as well as between humidity and temperature inversion depth, in the coastal Antarctic. On the other hand, the base height of humidity inversions has been reported to be generally higher compared to the base height of temperature inversions in polar regions (Vihma et al., 2011; Nygård et al., 2013). Vihma et al. (2011) concluded that this is probably due to the fact that the snow surface is usually a sink for sensible heat but not for water vapour, reducing the occurrence of surface-based humidity inversions.

Previous studies have provided somewhat incoherent estimates for humidity inversion occurrence in the Arctic. Devasthale et al. (2011) reported based on Atmospheric Infrared Sounder (AIRS) data that the fraction of humidity inversion occurrence in 2002-2010 was more than 0.50 in winter in clear-sky conditions over the Arctic Ocean. On the basis of tethersonde soundings on the central Arctic sea ice in AprilAugust 2007, Jakobson et al. (2012) detected a humidity inversion occurrence of $72 \%$. The number could have been even higher but, due to an icing risk, it was not possible to let the tethersonde rise into thick clouds. During a two-week measurement campaign on the coast of Svalbard in spring, humidity inversions were present in all tethersonde profiles taken (Vihma et al., 2011; Kilpeläinen et al., 2012). In summer, Devasthale et al. (2011) estimated based on AIRS data that the occurrence of humidity inversions is lower than 0.10 , whereas their analysis of radio-sounding data from two Arctic stations did not show a seasonality in the frequency of occurrence. This strongly suggests that humidity inversion statistics are dependent on the method applied. Nygård et al. (2013) presented comprehensive humidity inversion climatology for the coastal Antarctic based on $10 \mathrm{yr}$ of radiosounding data and compared the results with the findings of Devasthale et al. (2011) for the Arctic. However, Nygård et al. (2013) could not draw any firm conclusions on the differences in humidity inversions between the two polar areas due to different methods used in the studies.

In this paper, we present a $10 \mathrm{yr}$ (2000-2009) climatology of Arctic humidity inversions applying the same methodology as Nygård et al. (2013) for the Antarctic. This allows us to compare humidity inversion climatologies derived with different methods in the Arctic and also enables us to reliably compare humidity inversion climatologies between the two polar areas. The methodology of Nygård et al. (2013) includes analysis of all inversions in a profile in all-sky conditions utilizing radiosonde data from the enhanced version of the Integrated Global Radiosonde Archive (IGRA) (Durre et al., 2006; Durre and Yin, 2008). In the analysis, we pay special attention to the occurrence and properties of humidity inversions, as well as their temporal and spatial variability in the Arctic (Sect. 3). In addition, a statistical analysis on the connection between humidity and temperature inversions is presented. These results are finally compared to previously presented climatologies from the Arctic and Antarctic (Sect. 4). Our results can further be utilized in validation of weather prediction and climate models as humidity inversions are a robust metric to evaluate reproducibility of the thermodynamics in numerical models (Devasthale et al., 2011).

\section{Methods}

\subsection{Data}

In this study, radio-sounding data available from Arctic stations north of $65^{\circ} \mathrm{N}$ are utilized. All together 36 stations (6 in the Nordic sector, 18 in Russia, 8 in North America and 4 in Greenland) are included in the study (Fig. 1 and Table 1). The radio soundings are obtained from the enhanced version of IGRA, which is a freely available global data set of quality-assured radiosonde profiles and also includes several derived variables such as the geopotential height, water vapour pressure and relative humidity (Durre et al., 2006; Durre and Yin, 2008). The variables are given at the mandatory pressure levels defined by the World Meteorological Organization (WMO) and, in addition, at levels at which a sounding variable deviates from linearity. Having all these levels, however, depends on the input data available from various countries as their instrumentation and data analysis procedures vary (Table 1). As we only concentrate on the low-tropospheric humidity inversions, we analyse the radiosounding data from the surface to $500 \mathrm{hPa}$, where $95 \%$ of atmospheric water vapour is found (Serreze et al., 1995a). On average, Greenlandic and Nordic stations have 15 vertical levels below $500 \mathrm{hPa}$ in the IGRA archive, Russian stations 10 levels, and North American stations 18 levels. The lower number of vertical data levels at Russian stations compared to other sectors has to be considered when the results are interpreted. The description of quality assurance procedure of IGRA is given in Durre et al. (2006). The cloud cover data are taken from the synoptic observations from the Integrated Surface Data (ISD) archived at the National Climatic Data Center (NCDC) of National Oceanic and Atmospheric Administration (NOAA).

The selected study period covers the years 2000-2009. The period is the same as used in Nygård et al. (2013) for the Antarctic, and therefore it allows for a reliable comparison of results between the polar regions. The data are divided into four seasons applying the standard three-month classification, in which winter ranges from December to February, spring from March to May, summer from June to August 
Table 1. Radio-sounding stations included in the study: station names with their abbreviations, station heights above the sea level, coordinates, and radiosonde types* used in 2000-2009.

\begin{tabular}{|c|c|c|c|c|}
\hline Station & Abbr. & Height (m) & Coordinates & Radiosonde system \\
\hline Jan Mayen & JAN & 9 & $70.9^{\circ} \mathrm{S} / 8.7^{\circ} \mathrm{W}$ & Vaisala RS92 \\
\hline Ny-Ålesund & NYA & 8 & $78.9^{\circ} \mathrm{S} / 11.9^{\circ} \mathrm{E}$ & Vaisala RS92 \\
\hline Bodø & BOD & 20 & $67.3^{\circ} \mathrm{S} / 14.4^{\circ} \mathrm{E}$ & Vaisala RS92 \\
\hline Bjørnøya & BJO & 18 & $74.5^{\circ} \mathrm{S} / 19.0^{\circ} \mathrm{E}$ & Vaisala RS92 \\
\hline Luleå-Kallax & LUL & 34 & $65.6^{\circ} \mathrm{S} / 22.1^{\circ} \mathrm{E}$ & Vaisala RS92 \\
\hline Sodankylä & SOD & 178 & $67.4^{\circ} \mathrm{S} / 26.7^{\circ} \mathrm{E}$ & Vaisala RS92 \\
\hline Kandalaksa & KAN & 26 & $67.1^{\circ} \mathrm{S} / 32.4^{\circ} \mathrm{E}$ & Russia-USSR MRZ-3A/Russia-USSR AVK-RF95 \\
\hline Murmansk & MUR & 121 & $67.0^{\circ} \mathrm{S} / 33.1^{\circ} \mathrm{E}$ & Russia-USSR MRZ-3A/Russia-USSR AVK-RF95 \\
\hline Shoina & SHO & 10 & $67.9^{\circ} \mathrm{S} / 44.2^{\circ} \mathrm{E}$ & Russia-USSR MRZ-3A/Russia-USSR AVK-RF95 \\
\hline Malye Karmakuly & MAL & 19 & $72.4^{\circ} \mathrm{S} / 52.7^{\circ} \mathrm{E}$ & Russia-USSR Mars \\
\hline Nar’Jan-Mar & NAR & 9 & $67.7^{\circ} \mathrm{S} / 53.0^{\circ} \mathrm{E}$ & Russia-USSR MRZ-3A \\
\hline Pechora & PEC & 56 & $65.1^{\circ} \mathrm{S} / 57.1^{\circ} \mathrm{E}$ & Russia-USSR Mars/Russia-USSR MRZ-3A \\
\hline Salehard & SAL & 15 & $66.5^{\circ} \mathrm{S} / 66.5^{\circ} \mathrm{E}$ & Russia-USSR MRZ-3A \\
\hline Ostrov Dikson & OST & 47 & $73.5^{\circ} \mathrm{S} / 80.4^{\circ} \mathrm{E}$ & Russia-USSR Mars \\
\hline Turuhansk & TUR & 37 & $65.8^{\circ} \mathrm{S} / 88.0^{\circ} \mathrm{E}$ & Russia-USSR MRZ-3A/Russia-USSR AVK-RF95 \\
\hline Khatanga & KHA & 32 & $72.0^{\circ} \mathrm{S} / 102.5^{\circ} \mathrm{E}$ & Russia-USSR Mars \\
\hline Olenek & OLE & 203 & $68.5^{\circ} \mathrm{S} / 112.4^{\circ} \mathrm{E}$ & Russia-USSR MRZ-3A \\
\hline Zigansk & ZIG & 83 & $66.8^{\circ} \mathrm{S} / 123.4^{\circ} \mathrm{E}$ & Russia-USSR MRZ-3A \\
\hline Tiksi & TIK & 8 & $71.6^{\circ} \mathrm{S} / 128.9^{\circ} \mathrm{E}$ & Russia-USSR Mars/Russia-USSR MRZ-3A \\
\hline Verhojansk & VER & 137 & $67.6^{\circ} \mathrm{S} / 133.4^{\circ} \mathrm{E}$ & Russia-USSR MRZ-3A \\
\hline Chokurdakh & $\mathrm{CHO}$ & 48 & $70.6^{\circ} \mathrm{S} / 147.9^{\circ} \mathrm{E}$ & Russia-USSR MRZ-3A \\
\hline Zvbjanka & ZVB & 43 & $65.7^{\circ} \mathrm{S} / 150.9^{\circ} \mathrm{E}$ & Russia-USSR MRZ-3A \\
\hline Omolon & OMO & 253 & $65.2^{\circ} \mathrm{S} / 160.5^{\circ} \mathrm{E}$ & Russia-USSR MRZ-3A \\
\hline Cerskij & CER & 26 & $68.8^{\circ} \mathrm{S} / 161.3^{\circ} \mathrm{E}$ & Russia-USSR MRZ-3A \\
\hline Kotzebue & KOT & 5 & $66.9^{\circ} \mathrm{S} / 162.6^{\circ} \mathrm{W}$ & VIZ B 1492-520 \\
\hline Barrow & BAR & 12 & $71.3^{\circ} \mathrm{S} / 156.8^{\circ} \mathrm{W}$ & VIZ B 1492-520 \\
\hline Norman Wells & NOR & 95 & $65.3^{\circ} \mathrm{S} / 126.8^{\circ} \mathrm{W}$ & Canada Valcom \\
\hline Cambridge Bay & CAM & 25 & $69.1^{\circ} \mathrm{S} / 105.1^{\circ} \mathrm{W}$ & Canada Valcom \\
\hline Resolute Bay & RES & 40 & $74.7^{\circ} \mathrm{S} / 95.0^{\circ} \mathrm{W}$ & Canada Valcom \\
\hline Eureka & EUR & 10 & $80.0^{\circ} \mathrm{S} / 85.9^{\circ} \mathrm{W}$ & Canada Valcom \\
\hline Hall Beach & HAL & 7 & $68.6^{\circ} \mathrm{S} / 81.3^{\circ} \mathrm{W}$ & Canada Valcom \\
\hline Alert & ALE & 66 & $82.5^{\circ} \mathrm{S} / 62.3^{\circ} \mathrm{W}$ & Canada Valcom \\
\hline Egedesminde & EGE & 41 & $68.7^{\circ} \mathrm{S} / 52.9^{\circ} \mathrm{W}$ & Vaisala RS92 \\
\hline Angmagssalik & ANG & 52 & $65.6^{\circ} \mathrm{S} / 37.6^{\circ} \mathrm{W}$ & Vaisala RS92 \\
\hline Scoresbysund & $\mathrm{SCO}$ & 69 & $70.5^{\circ} \mathrm{S} / 22.0^{\circ} \mathrm{W}$ & Vaisala RS92 \\
\hline Danmarkshavn & DAN & 59 & $76.8^{\circ} \mathrm{S} / 18.8^{\circ} \mathrm{W}$ & Vaisala RS92 \\
\hline
\end{tabular}

* The IGRA data do not include complete information of the radiosonde types. The correct type is shown here when information has been available.

and autumn from September to November. During the study period, the total amount of radio-sounding profiles per station varies between 1800 and 7300 . At all the stations, the data are fairly evenly distributed between years and months. The Russian stations Khatanga, Cerskij and Omolon are the only exceptions to this as no sounding data from these stations are available from the first $2-3$ study years. The observation times are clustered around 00:00 UTC and 12:00 UTC. Due to different longitudes of the stations, the solar time of observations varies largely, and hence the diurnal cycle cannot be studied.

\subsection{Analysis methods}

Humidity inversion layers below $500 \mathrm{hPa}$ are identified from the specific humidity profiles, which are calculated from the observed water vapour pressure and air pressure profiles of IGRA. In cold and dry conditions, errors in the humidity profiles can be relatively large (Nash et al., 2006, 2011). In addition, saturated conditions during the radiosonde flight might generate errors in humidity measurements, particularly if the sensor is not equipped with a heating system to minimize the condensation. As the errors vary with the sensor type (Table 1) and the data have gone through quality control procedures, we do not attempt any humidity additional corrections to the IGRA data. To reduce the errors in our study, 


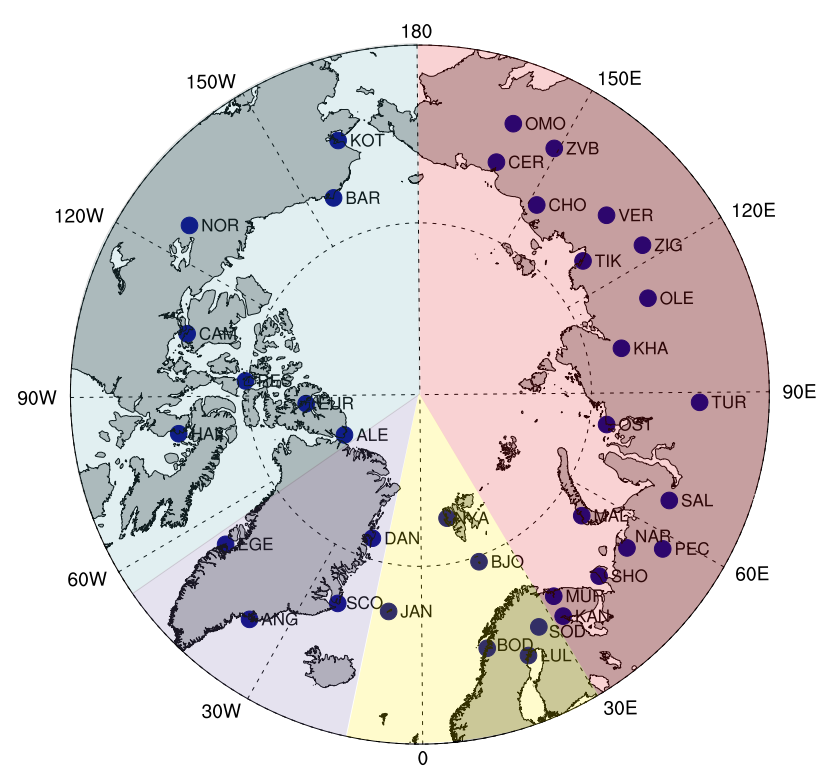

Fig. 1. Locations of the radio-sounding stations in the Arctic. The full station names are given in Table 1 . The shaded areas indicate the geographical sectors used in this study.

we do, however, exclude humidity profiles from the surface to $500 \mathrm{hPa}$ in which the temperature is below $-40^{\circ} \mathrm{C}$ and the relative humidity is below $20 \%$ or, alternatively, the specific humidity is below $0.2 \mathrm{~g} \mathrm{~kg}^{-1}$. More detailed considerations of errors in humidity profiles can be found in Nygård et al. (2013).

For each humidity inversion layer, an inversion strength, depth and base height are determined. The base height is defined to be the level at which the specific humidity starts to increase with altitude. The inversion depth is defined to be the difference between the base height and the level at which the specific humidity starts to decrease with altitude. An inversion is defined to be surface-based if the base height is located below $50 \mathrm{~m}$ altitude. All the levels are given as heights from the ground/snow surface. The inversion strength is defined as the difference in specific humidity between the inversion top and base. Similarly as in Nygård et al. (2013), a selection criteria is used where a humidity inversion has to be deeper than $10 \mathrm{~m}$ and separated by a layer of a negative humidity lapse rate. We do not apply any minimal depth to the separating layer of negative lapse rate. Temperature inversions are identified applying similar definitions as for humidity inversions, but the minimum strength of temperature inversions is set to $0.3^{\circ} \mathrm{C}$ following Kilpeläinen et al. (2012) and Nygård et al. (2013). Figure 2 provides an example of observed humidity and temperature inversions; there are three separate humidity inversions in the profile, one of them approximately collocated with a temperature inversion and two of them without a temperature inversion in the nearby layers.
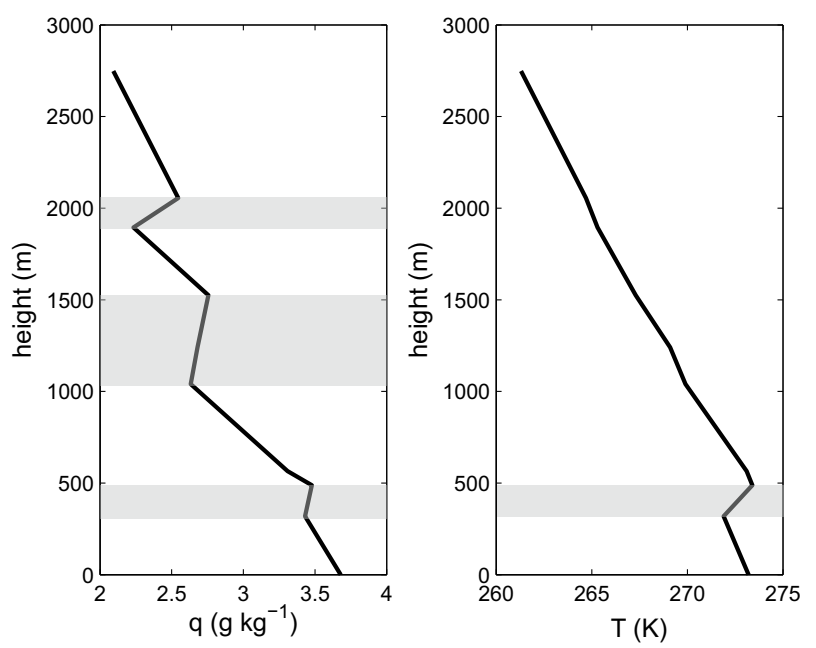

Fig. 2. Specific humidity and temperature profiles observed in Alert on 22 August 2005, 00:00 UTC. The grey shading marks the inversion layers.

In the analysis of inversion statistics, we mostly focus on the median values as the arithmetic mean values are notably affected by the positively skewed distributions of inversion properties. The statistical significance of differences of humidity inversion properties in different cloud conditions is tested applying the Mann-Whitney $U$ test, which is a nonparametric test of the null hypothesis that two populations are the same. In other words, the test does not require normally distributed data.

\section{Results}

\subsection{Humidity inversion characteristics}

The analysis of the statistics of humidity inversion properties showed that humidity inversions were very frequent at all the Arctic stations studied (Fig. 3a). At the majority of Nordic, North American and Greenlandic stations, the occurrence of humidity inversions was higher than 0.9 throughout the year. Furthermore, at all the stations the occurrence of humidity inversions was higher than the occurrence of temperature inversions; the difference between humidity and temperature inversion occurrence at each station was on average 0.07 . The seasonal variation in humidity inversion occurrence was small, except for the eastern part of Russian Arctic, where the occurrence was $0.1-0.2$ lower in summer compared to the other seasons. The pronounced seasonal cycle of the inversion occurrence in the eastern part of Russia is probably closely connected to seasonal variation of atmospheric temperature and humidity, which are extreme in the area. The mean number of humidity inversions in a profile varied between 1.3 and 4.0 between the stations and was highest in the North American sector and lowest in the Russian sector 
(Fig. 3b). However, the number notably reflected the vertical resolution of data available in each sector (see Sect. 2.1). For example, Sodankylä (Nordic sector) and Kandalaksa (Russian sector) are located only $250 \mathrm{~km}$ apart and represent approximately the same climatic conditions, but the mean number of humidity inversions was 2.7 for Sodankylä and only 1.9 for Kandalaksa, where fewer vertical data levels were available.

Humidity inversion strength was clearly highest in summer (Fig. 3c) as the moisture content of the air was several times higher in summer than in winter. The strongest humidity inversions were found in the Nordic and North American sectors in summer. Spatial differences in the whole year median strengths were very small. Russian humidity inversions were deeper than inversions elsewhere in the Arctic (Fig. 3d). This is mainly a result of many humidity inversions being connected to the lowest near-surface temperatures (Rigor et al., 2000) and the deepest temperature inversions of the Arctic region occurring in Siberia in winter (see Sect. 3.2), although a part of the spatial difference is also explained by the fact that the Russian sounding data contained less vertical levels. Typically, Russian humidity inversions were located near the surface, especially in winter, whereas the median base height of other Arctic stations was well above $1000 \mathrm{~m}$ altitude (Fig. 3e). Humidity inversions generally had the highest base in summer. The fraction of surface-based humidity inversions was smaller than 0.2 at the Nordic, North American and Greenlandic stations, whereas at the Russian stations the fraction was $0.2-0.5$, having a clear maximum in winter (Fig. 3f). The average fraction of surface-based humidity inversions over all the Arctic stations was 0.22 , whereas the average fraction of surface-based temperature inversions was larger, being 0.31 .

Next we address the sensitivity of inversion statistics to the calculation method. We do this because detailed knowledge on the sensitivity is a prerequisite for meaningful comparison of studies based on different methodology. When only the strongest humidity inversion in a profile was considered, the median inversion strength at each station was on average $0.45 \mathrm{~g} \mathrm{~kg}^{-1}$, compared to $0.23 \mathrm{~g} \mathrm{~kg}^{-1}$ for all inversions. On the other hand, when only the strongest inversion in a profile in clear-sky conditions was considered, as was done by Devasthale et al. (2011) for the AIRS data, the median inversion strength at each station was on average $0.42 \mathrm{~g} \mathrm{~kg}^{-1}$ (Fig. 4). These results indicate that focusing only on the strongest inversion, either in all-sky or clear-sky conditions, gives inversions in the Arctic that are approximately twice as strong compared to results with all inversions included. Furthermore, when only the strongest inversions in all-sky conditions were analysed, the median base height of inversions was on average nearly $500 \mathrm{~m}$ lower than that of all inversions (Figs. 3 and 4). The median base height of strongest clear-sky inversions, in turn, was at the surface at nearly all the Russian and North American stations. Hence, the difference between the median base height of all inversions and the strongest clear-sky inversions was several hundreds of metres; at North American stations the difference was even more than $1000 \mathrm{~m}$. The depth of inversion layer did not notably vary between the above-mentioned data categories.

Another methodological aspect is to study the sensitivity of the results to our practice of analysing all humidity inversions separately. We made similar sensitivity tests as in Nygård et al. (2013). These showed that if a layer up to $200 \mathrm{~m}$ thick with specific humidity decreasing with height is allowed between the inversion layers, the statistics were affected as follows: (a) the number of inversions in a profile was on average $0.3(14 \%)$ smaller, (b) the inversion was on average $0.002 \mathrm{~g} \mathrm{~kg}^{-1}(0.1 \%)$ weaker, and (c) the inversion layer was on average $20 \mathrm{~m}(6 \%)$ thinner than in the case that all inversion layers are analysed separately. Accordingly, sensitivity to the inversion definition was weak.

Humidity inversions generally occurred more frequently in clear-sky conditions (average inversion occurrence 0.95 ) than in overcast conditions (average inversion occurrence 0.91). Although the difference was small, it was systematic for almost all stations (Fig. 5a). Overcast conditions represented, on average, $44 \%$ of the sounding data, and clearsky conditions $22 \%$ of the data, having minima (5-7\%) at stations Jan Mayen and Bjørnøya located on small islands in the Nordic sector. Compared to overcast cases, the median strength of clear-sky humidity inversions was higher at the Nordic, North American and Greenlandic stations, but typically lower at the Russian stations (Fig. 5c). At 22 of the stations, the difference in the inversion strength between the clear-sky and overcast conditions was statistically significant. At 32 of the stations, the depth of humidity inversions was significantly higher in clear-sky conditions (Fig. 5d). The base height of humidity inversions was typically lower in clear-sky conditions (Fig. 5e), especially at the Russian stations, and these differences were statistically significant elsewhere than in the Nordic sector. The lower base height in clear-sky conditions at the Russian stations also reflected the much higher surface-based inversion fraction in clear-sky conditions; nearly half of the Russian humidity inversions were surface-based in clear-sky conditions, while in overcast conditions the fraction was only around 0.2 (Fig. 5f). On average, the base height was $240 \mathrm{~m}$ lower in clear-sky conditions compared to overcast conditions in the Arctic (Fig. 5e). The number of inversions in a profile was not clearly connected with cloud conditions (Fig. 5b).

The mean and median values presented in Figs. 3-5 do not provide all essential information on inversion properties. Hence, relative frequency distributions (RFDs) indicated that distributions of humidity inversion number were different in each Arctic sector (Fig. 6). Russian stations had typically two inversions per profile, and more than three inversions per profile were rarely found there. In the other sectors, on the other hand, the distribution of inversion number was more skewed towards higher numbers, and most commonly 3-4 inversions were found in a profile. This, again, indicates the impacts 

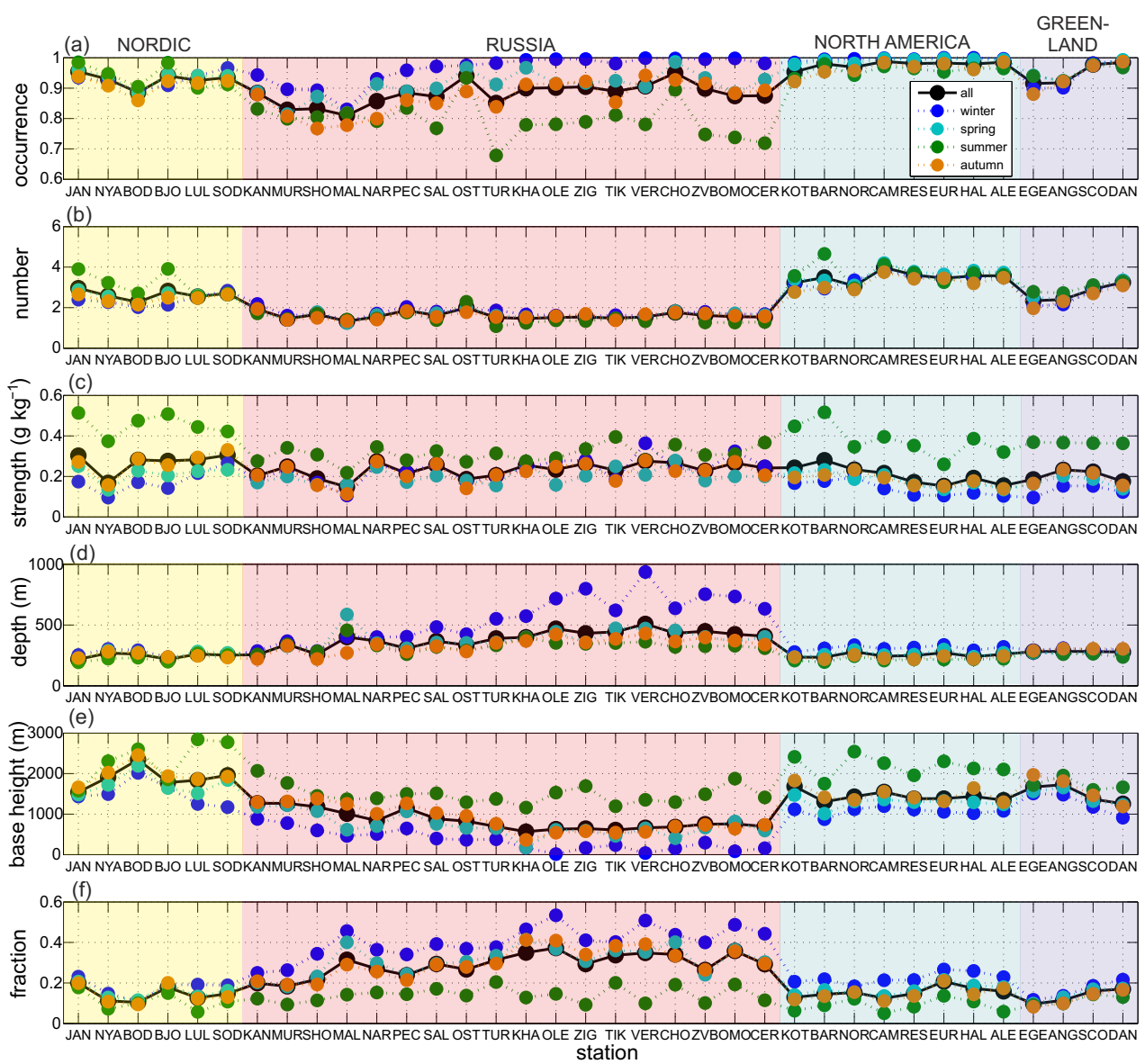

Fig. 3. (a) Occurrence of humidity inversions, (b) mean number of humidity inversions in a single profile, (c) median strength, (d) median depth and (e) median base height of humidity inversions, and (f) the fraction of surface-based humidity inversions.

of lower amount of vertical levels at the Russian stations. Interestingly, the distributions of other humidity inversion properties in the Russian sector did not deviate notably from the other sectors. This suggests that most humidity inversion properties have a quite universal shape of RFDs everywhere in the Arctic. Shapes of RFDs were not strongly affected by cloud conditions, except that surface-based and weak inversions were more common under clear-skies and thin inversions were more common under overcast skies (Fig. 6). At all the Arctic stations, the RFDs of humidity inversion strength had a nearly exponential shape. The RFDs of inversion depth peaked between 100 and $200 \mathrm{~m}$, and then decreased towards the larger depths. The RFDs of base height had a pronounced maximum at the surface, and two systematic minor maxima at $1400 \mathrm{~m}$ and between 2600 and $3000 \mathrm{~m}$, but apart from those the base heights they were fairly equally distributed between the altitudes. Figure $6 \mathrm{~d}$ helps us to better understand the median based heights shown in Fig. 5e; the lower median values in the Russian stations (Fig. 5e) are related to a particularly high occurrence of base heights less than $400 \mathrm{~m}$ and a particularly low occurrence of base heights more than
2000 m (Fig. 6d). In the Nordic sector with high values, the situation is reversed. See Sect. 4 for more discussion.

Occurrence of humidity inversions was clearly dependent on the pressure, whereas the other inversion properties did not show as clear dependency on the pressure (Fig. 7). At 31 of the stations, a positive Spearman correlation between inversion occurrence and sea level pressure was statistically significant $(p<0.05)$. The Spearman correlation denotes the strength of the monotonic relationship, which is not necessarily linear. The dependency between the occurrence of humidity inversions and sea level pressure was clearest at the Russian stations. The relationship between the inversion strength and sea level pressure was statistically significant at 10 stations, and these stations were distributed in all the Arctic sectors; however, the sign of the correlation varied between the stations and no general pattern was recognized. A positive correlation between the inversion depth and sea level pressure was statistically significant at six Russian stations (Fig. 7b), and a significant correlation of varying sign between the inversion base height and sea level pressure was 


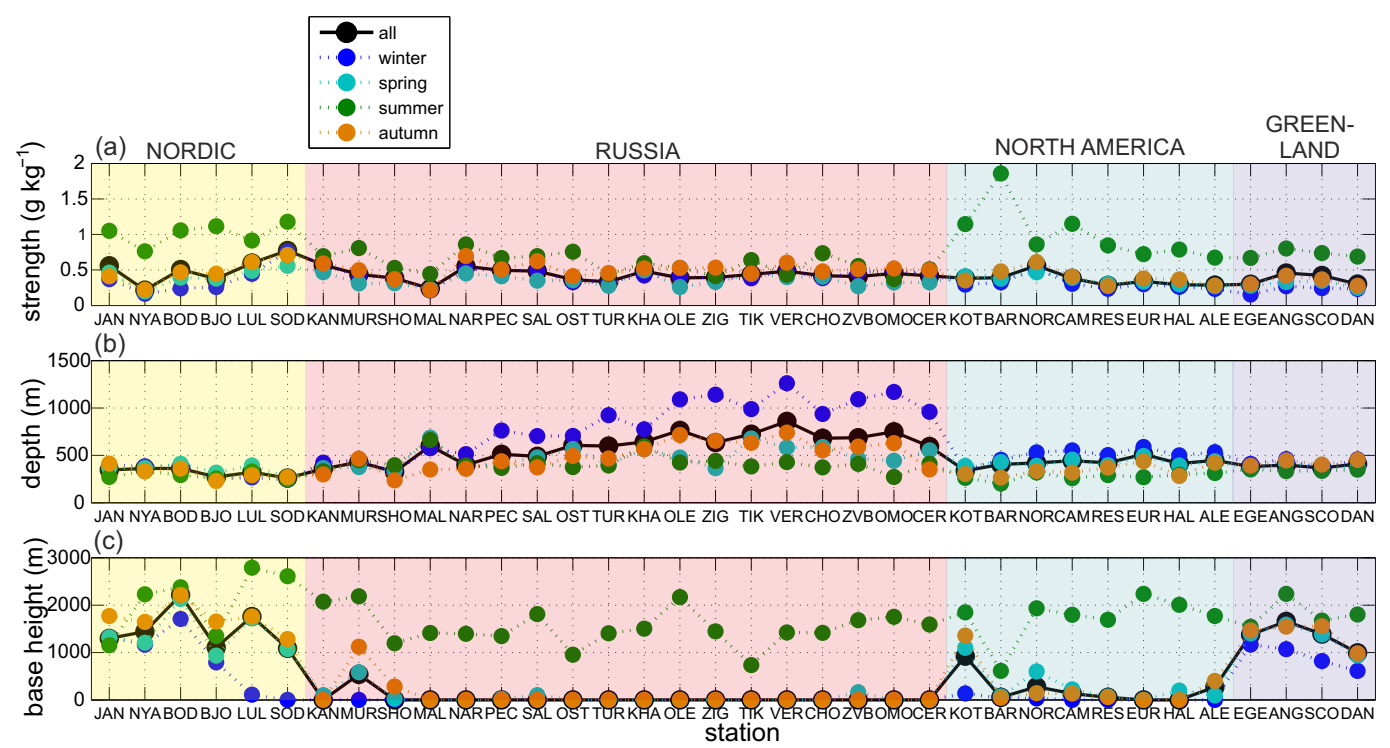

Fig. 4. (a) Median strength, (b) median depth and (c) median base height of the strongest humidity inversion in a profile in clear-sky conditions.
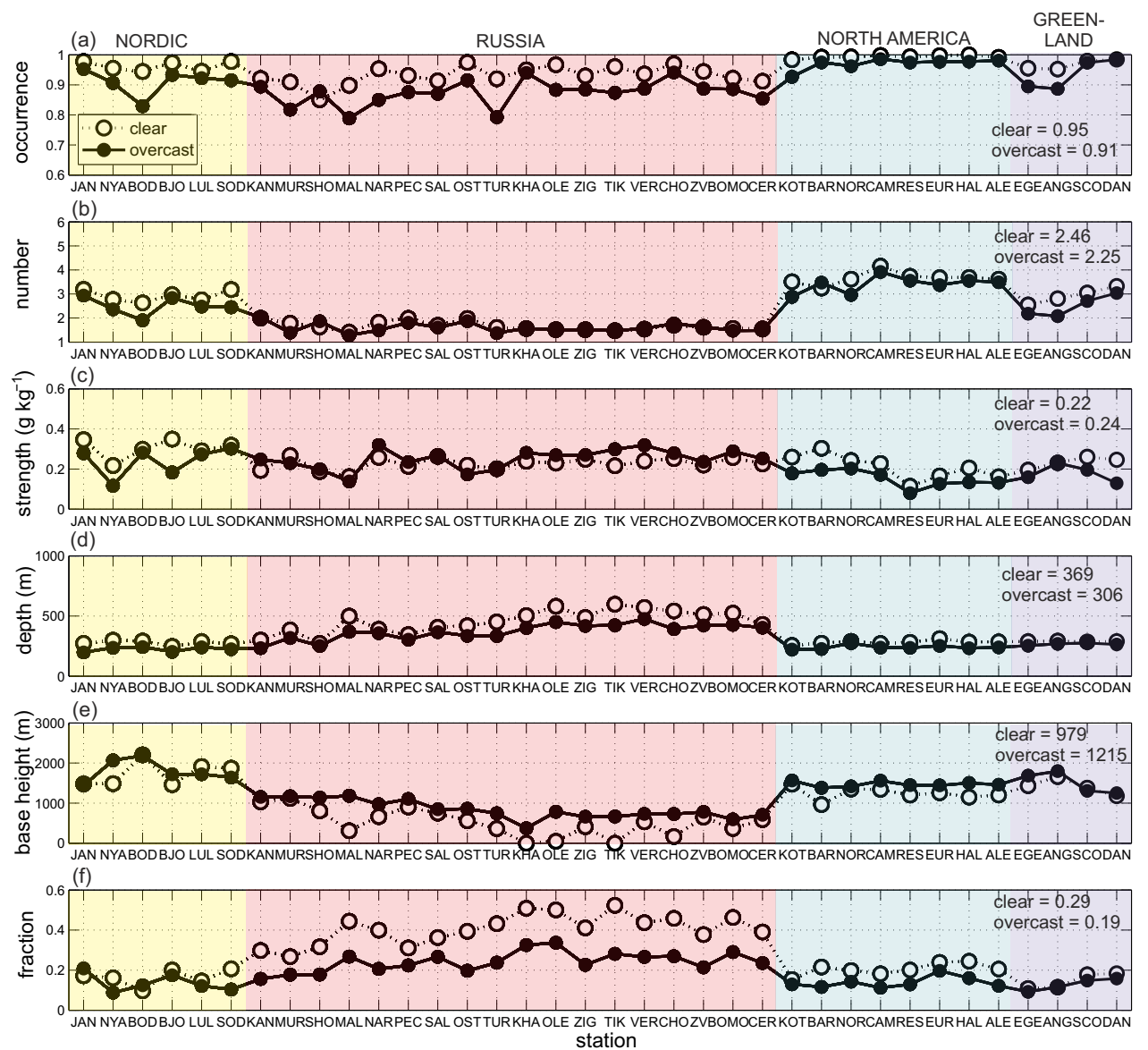

Fig. 5. (a) Occurrence of humidity inversions, (b) mean number of humidity inversions in a single profile, (c) median strength, (d) median depth and (e) median base height of humidity inversions, and (f) the fraction of surface-based humidity inversions in clear-sky and overcast conditions. Averages over all the Arctic stations are given (on the right) for clear-sky and overcast conditions separately. 

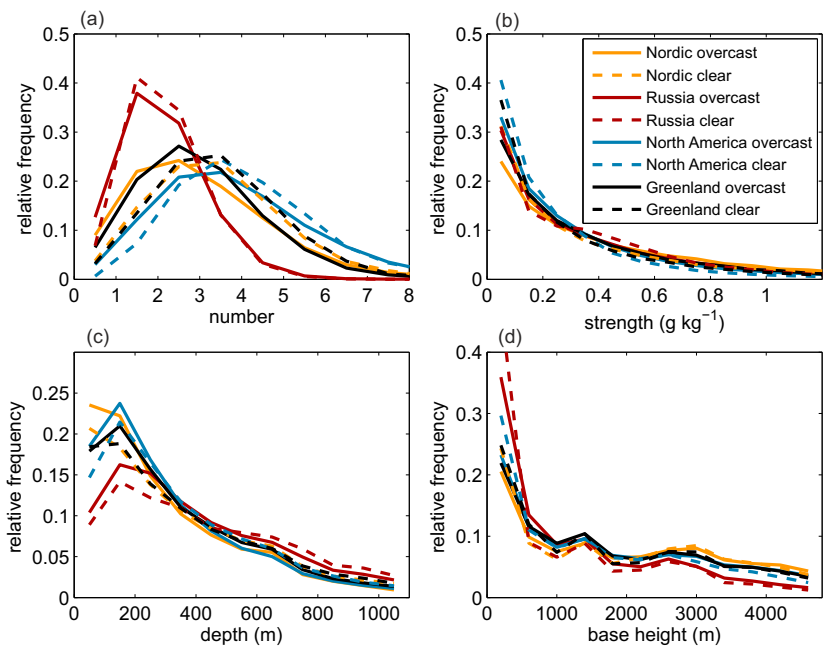

Fig. 6. Relative frequency distributions RFDs of (a) number of humidity inversions in a single profile, (b) inversion strength, (c) inversion depth and (d) inversion base height at each station in the geographical sectors. Bin sizes used in the RFDs are 1 for the inversion number, $0.1 \mathrm{~g} \mathrm{~kg}^{-1}$ for the inversion strength, $100 \mathrm{~m}$ for the inversion depth and $200 \mathrm{~m}$ for the inversion base height.

found at four stations: Jan Mayen, Nar'Jan-Mar, Tiksi and Scoresbysund.

\subsection{Relationships between humidity and temperature inversions}

Many of the humidity inversions in the Arctic appeared to be connected with temperature inversions. However, the fraction of humidity inversions occurring at least partly within the same layer with temperature inversions had large spatial variability (Fig. 8). Whereas more than $60 \%$ of humidity inversions in the Russian Arctic were accompanied by a temperature inversion, the corresponding fraction was less than $30 \%$ in North America. Again, Sodankylä and Kandalaksa, nearby stations in different sectors, had fairly different results (Sodankylä 37\% and Kandalaksa 52\%), reflecting the impacts of the number of vertical data levels available. This suggests that the generally higher proportion of humidity inversions connected to temperature inversions in the Russian sector was at least partly related to methodology. It is, however, very difficult to quantify the exact contributions of methods and climatic conditions for the distinctive results of the Russian sector. Nevertheless, Arctic humidity inversions cannot only be considered as accompanying phenomena for temperature inversions because a large portion of humidity inversions occurred in layers vertically independent (not overlapping) of temperature inversion layers. The seasonal cycle of the fraction of humidity inversions occurring together with temperature inversions varied largely between the stations and no general pattern was recognized.
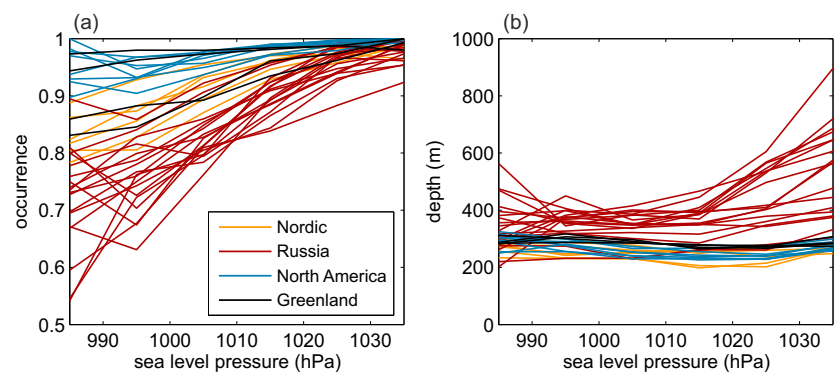

Fig. 7. Dependency between sea level pressure and (a) occurrence, and (b) median depth of humidity inversions at each station.

Humidity inversion properties were temporally correlated (Spearman correlation) with each other, and also with temperature inversion properties (Fig. 9). It was, however, much more common that temperature inversion properties were dependent on each other than that humidity inversion properties were connected to each other. For example, no statistical connection between humidity inversion strength and humidity inversion base height was found (except at Omolon), although temperature inversion strength was correlated with temperature inversion base height at nearly all the stations. In addition, a significant correlation between the strength and depth was not as common and strong for humidity inversions as it was for temperature inversions. Generally, the base heights of humidity and temperature inversions were positively correlated, and the humidity inversion base height had a negative correlation with temperature inversion strength. The latter correlation means that the strongest humidity inversion in a profile was likely to be located close to the surface when simultaneously occurring temperature inversion was strong. Humidity and temperature inversion depths, as well as humidity and temperature inversion strengths correlated positively (Fig. 9), although only $48 \%$ of humidity inversions were found to accompany temperature inversions (Fig. 8). This suggests that even if the humidity and temperature inversions occurred in different vertical layers, the prevailing meteorological or surface conditions influenced both humidity inversion and temperature inversion properties in a similar manner.

\section{Discussion}

It is evident that humidity inversions are predominantly present in the Arctic atmosphere. Our results confirm that humidity inversion statistics are nonetheless very sensitive to the methodology. For example, many studies on Arctic temperature inversions have only focused on the surface-based temperature inversions, but according to our findings, such a surface-based focus is too restrictive for humidity inversions as nearly $80 \%$ of Arctic humidity inversions are elevated from the surface. Humidity inversions are, however, fairly often connected to temperature inversion layers, as was also 


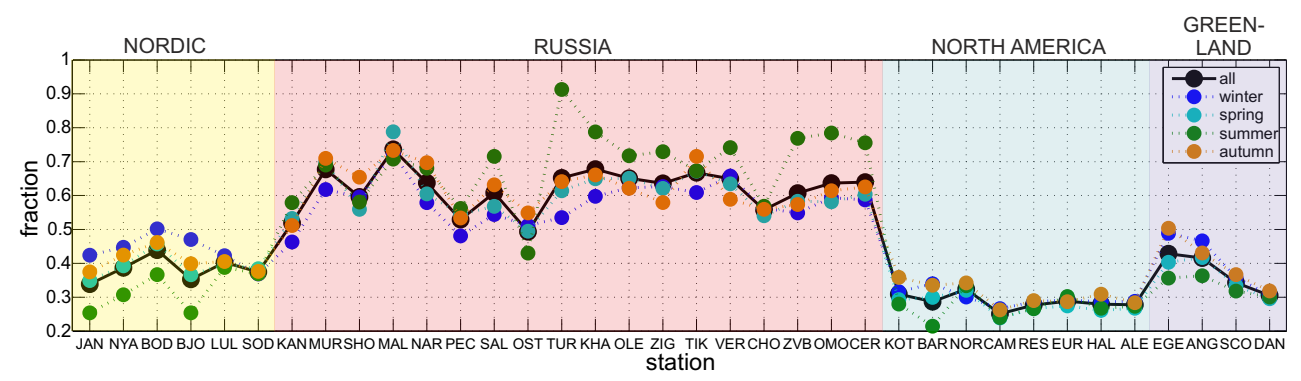

Fig. 8. Fraction of humidity inversions which occurred simultaneously with a temperature inversion at least partly within the humidity inversion layer.

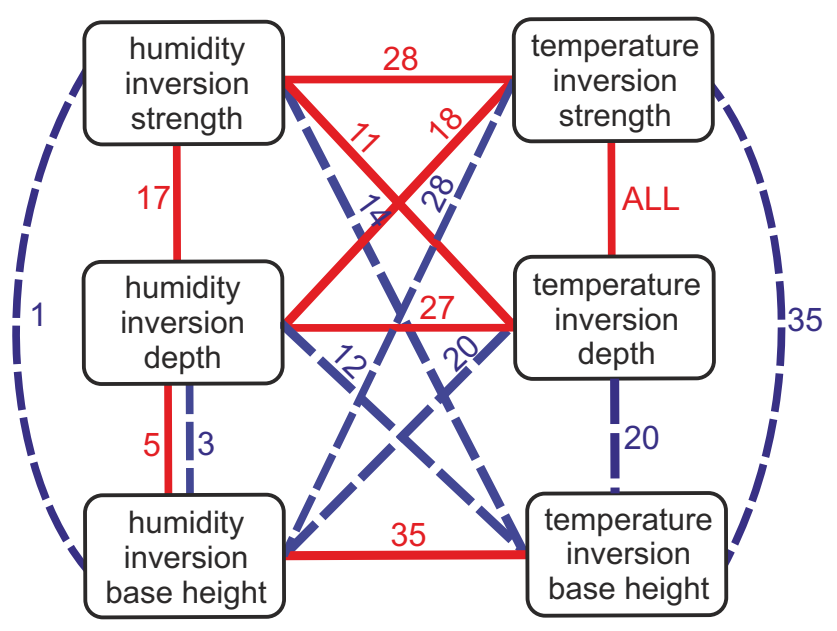

Fig. 9. Schematic presentation of temporal correlation between humidity inversion and temperature inversion properties (only the strongest humidity and temperature inversion in a profile are considered). The red solid lines indicate a significant positive correlation, and blue dashed lines a significant negative correlation (correlation coefficient $-0.20<r>0.20, p<0.01$ ). The numbers denote the amount of stations at which the correlation was found.

shown in the present study. Nevertheless, it is apparent that the surface more often acts as a sink for sensible heat than for water vapour (Persson, 2002; Vihma et al., 2011), and therefore it is reasonable that the surface-based humidity inversions are less common than surface-based temperature inversions. Theoretically seen, the occurrence of surface-based humidity inversions in a location can only be lower or equal to the occurrence of surface-based temperature inversions. This is nevertheless true only for those humidity inversions that have their base strictly at the surface (and not higher up in the lowermost $50 \mathrm{~m}$ as was allowed in this study due to lack of actual surface data). The reason for limited occurrence of surface-based humidity inversions is that the air right at the snow surface is always saturated with respect to ice. Hence, the specific humidity cannot increase with height without temperature increasing with height, as schematically illustrated in Fig. 10. An exception to this is a case with a lack of condensation nuclei for ice crystals (Mauritsen et al., 2011) when the air specific humidity may exceed the saturation specific humidity of the snow surface even without the presence of a temperature inversion.

Of all the humidity inversions, $52 \%$ occurred vertically independent from temperature inversions, which also means that humidity inversions cannot be considered as only accompanying phenomena for temperature inversions. Sedlar and Tjernström (2009), Solomon et al. (2011) and Sedlar et al. (2012) found, however, that inversions of temperature and humidity typically coincide near the cloud top. A potential explanation for the different results is that the abovementioned studies mostly addressed the ice-covered Arctic Ocean, whereas the IGRA data set is more representative of the pan-Arctic land areas. On the basis of the limited observational and modelling information available, in summer the sensible and latent heat fluxes have larger magnitudes over pan-Arctic land areas than sea ice (Persson et al., 2002; Kållberg et al., 2005; Grachev et al., 2012). Larger flux magnitudes allow larger instantaneous differences between the sensible and latent heat fluxes, which tends to weaken the link between temperature and humidity inversions. In winter, both sensible and latent heat fluxes are small over sea ice (Persson et al., 2002), but larger downward sensible heat fluxes with near-zero moisture fluxes prevail over land (Kållberg et al., 2005). This weakens the link between temperature and humidity inversions over land in winter.

Some previous studies on vertical humidity profiles, e.g. Tjernström et al. (2004), have focused on the specific humidity difference across the temperature inversion layer. The approach provides information on the relation of temperature and humidity inversions, but does not provide representative statistics of all humidity inversions. Based on the findings of Nygård et al. (2013) for Antarctic humidity inversions, it is reasonable to believe that also a large portion of the Arctic humidity inversions may be connected to vertically uneven horizontal moisture flux (Jakobson and Vihma, 2010). According to estimates of Serreze et al. (1995b) and Overland and Turet (1994) based on radio soundings, zonal and meridional water vapour fluxes peak at approximately $850 \mathrm{hPa}$ in winter in the Arctic. This is in line with our finding that 

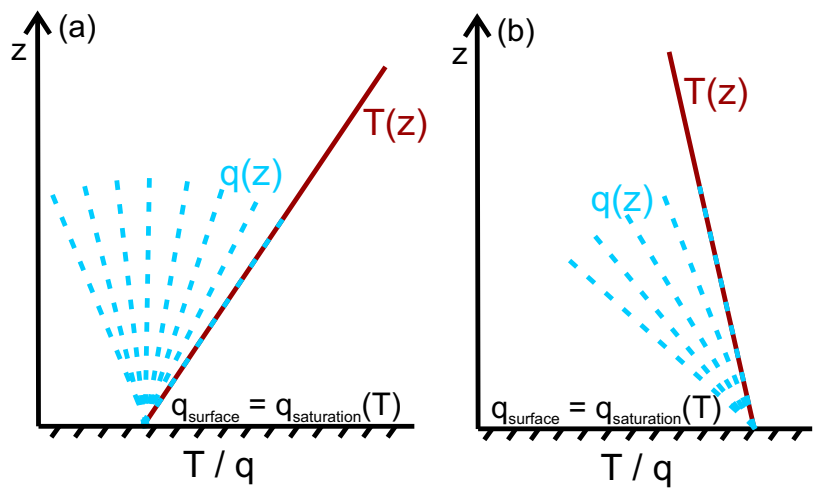

Fig. 10. Schematic presentation of potential profiles of specific humidity for two cases of air temperature profiles: (a) when a surfacebased temperature inversion is present, a surface-based humidity inversion can occur. On the other hand, (b) when there is no surfacebased temperature inversion, a surface-based humidity inversion cannot occur.

many elevated humidity inversions have their base at around $1400 \mathrm{~m}$, as indicated by RFDs in Fig. 6, and thereby the finding supports a conclusion that large-scale horizontal moisture fluxes, and their vertical distribution, have a notable impact on the humidity inversions in the Arctic.

Despite the fact that approximately half of the humidity inversions occurred vertically separate from temperature inversions, we found that the prevailing meteorological conditions have an impact on both humidity inversions and temperature inversions, and properties of the strongest humidity and temperature inversion in a profile are often correlated. Furthermore, our results give support to the findings of Vihma et al. (2011) and Nygård et al. (2013) that humidity inversion properties are statistically quite independent from each other. Thus, in contrast to temperature inversions, strength and depth of a humidity inversion are commonly unrelated to the base height of the humidity inversion, and statistical connection between the humidity inversion strength and depth is weak in many locations in the Arctic. Reasons for this weak connection between humidity inversion properties are difficult to identify and so far remain unclear.

Our humidity inversion statistics for the Arctic differ remarkably from the statistics presented by Devasthale et al. (2011) based on the AIRS data. The results of Devasthale et al. (2011) indicated a very strong seasonal cycle of humidity inversion occurrence, with a range of approximately 0.7, in the Russian and North American sectors, and an inversion occurrence below 0.4 throughout the year in the Nordic sector and the southern part of Greenland. According to our results, humidity inversion occurrence is in turn higher than 0.6 in all seasons at all the stations, and the seasonal cycle of inversion occurrence was notable only in the Russian sector, having a range of 0.2. Our results for inversion strength agree with those of Devasthale et al. (2011) for the summer sea- son, but for the other seasons our median inversion strength is clearly higher. The difference in inversion strength is even higher when our results for the strongest humidity inversion in a profile in clear-sky conditions are considered, following the methodology of Devasthale et al. (2011). These large differences arise from the different study regions, instruments, vertical resolution and methodologies applied. In the Central Arctic (studied by Devasthale et al. 2011), leads in sea ice and other open water areas are a humidity source also in the winter. In our study area, which is mostly inland and archipelago, similar notable moisture sources at the surface are not available in winter. Other differences in the statistics are not as apparently related to the different study regions, although the effect cannot be ruled out. It is also worth noting that the radio-sounding analysis of Devasthale et al. (2011) differed from their AIRS results, being closer to what we saw in this study. The clear-sky humidity inversion statistics presented by Devasthale et al. (2011) did not vary significantly from all-sky statistics, but it is important to note that they only compared the strongest inversion in a profile in clear-sky and all-sky conditions. Indeed, also in our study the median strength and depth of the strongest clear-sky humidity inversions were similar to the median strength and depth of the strongest all-sky inversions humidity inversions, although the base height was notably lower in the strongest clear-sky inversions. The conclusion, which has already been arrived at by Devasthale et al. (2011), that the humidity inversion properties do not vary largely with cloud cover therefore seems valid. On the other hand, pronounced differences in inversion strength, depth and base height were seen between all inversions and the strongest inversions. The differences underline impacts of methodology on the inversion statistics, and should be kept in mind in future studies. Although the satellite-derived water vapour profiles of AIRS provide a good spatial and temporal coverage of data, their vertical resolution is presently not comparable with radio-sounding data.

We also included the smallest detectable humidity inversions in the statistical analyses, but the data are not sufficient to quantitatively analyse how they affect physical processes. Considering the radiative transfer under clear skies, the smallest individual humidity inversions are probably of a minor importance, but they are potentially more important for the formation of a layered cloud cover, which is typical for the Arctic. From the point of view of clouds, not the magnitude of the humidity inversion but its relationship with the temperature profile is essential. Hence, even a small vertical difference in the air humidity may be important for the occurrence of condensation or for the rate of evaporation from existing cloud droplets or ice crystals. The formation of layered clouds also strongly reduced cloud-top radiative cooling of the lower clouds and hence reduces turbulent mixing inside and below the lower clouds (Shupe et al., 2013). Accordingly, even the smallest humidity inversions may have 
a large indirect effect on the radiative transfer and turbulent mixing in the Arctic troposphere.

Compared to the characteristics of humidity inversions in the Antarctic derived applying the same methodology (Nygård et al., 2013), we found that the Arctic humidity inversions are, in general, quite similar. In both polar regions, the occurrence of humidity inversions is well above 0.6 in all seasons, being highest when the atmospheric pressure is high, and the inversions are typically found on two or more levels. However, in the Antarctic, the seasonal variability was low in most inversion properties, whereas the Arctic stations experience larger differences between the seasons, particularly in the median strength, median base height and the fraction of surface-based humidity inversions. The larger seasonal variability of inversions in the Arctic compared to the Antarctic inversions reflects the more pronounced seasonal cycle of other climate variables like the snow cover, air temperature and air humidity in the Arctic.

The relation of humidity inversions with cloud cover is relatively weak both in the Arctic and the Antarctic. In both regions, the occurrence and number of humidity inversions are mainly higher and the base height is lower in clear-sky situations. In the Antarctic, clear-sky inversions were stronger than overcast ones, but in the Arctic, no consistent relationship between the strength and the cloud cover was found. Arctic humidity inversions were deeper everywhere under clear-sky conditions, whereas the relationship between the humidity inversion depth and cloud cover varied between the stations in the Antarctic. Hence, the relationship between cloud cover and the depth and strength of humidity inversions seems to be different between the polar regions, and understanding reasons for the differences requires further studies.

Earlier attempts to investigate whether humidity inversions properties differ between the polar regions (Nygård et al., 2013) have not been fully reliable due to the different methodology used. Previously it was not possible to distinguish whether the suggested different characteristics were related to physiographical differences and dynamic/thermodynamic reasons or simply to different instrumentation, methodologies and vertical resolutions. Nygård et al. (2013), for example, suggested that humidity inversions have higher occurrence in the Antarctic than in the Arctic, and that the base height would have opposite seasonal cycle in the two polar regions. When applying the same type of data and analysis, we now find that the humidity inversions are about equally common in the Arctic and Antarctic and have a similar seasonal cycle of the base height that is higher in the summer than in the winter, although the ranges of the seasonal cycle are different.

In addition to differences in humidity inversion occurrence and properties between the Arctic and Antarctic, we observed large spatial differences within the Arctic. Some of them may be explained by previous results on climatology and large-scale transport of air moisture. The strongest humidity inversions were found in the Nordic and North
American sectors in summer. In the Nordic sector, the high summertime vertically integrated air moisture (Jakobson and Vihma, 2010) provides favourable preconditions for generation of strong humidity inversions. Although the seasonal variation in humidity inversion occurrence was small in general, in the eastern part of Russian Arctic the occurrence was lower in summer compared to the other seasons (Fig. 3a). This may be partly due to lack of major horizontal moisture transport in this region in summer (Jakobson and Vihma, 2010), reducing the inversion generation by advection.

The base height of humidity inversions is typically lower in clear-sky conditions compared to overcast conditions (Fig. 5e), especially at the Russian stations. These differences are, however, not statistically significant in the Nordic sector. This may be related to the presence of large sea areas in the Nordic sector. Over the open ocean at high latitudes, the surface is a large moisture source and the cloud cover does not have a major effect on the surface temperature. Hence, as the cloud cover does not control the occurrence of surface-based inversions via surface temperature, it is understandable that the differences in the base height between cloudy and clearsky cases are not so evident over the open sea. Conversely, in the Russian sector, the clear-sky conditions in winter were related to very low base heights, and at North American stations the difference between the median base height of all inversions and the strongest clear-sky inversions was more than $1000 \mathrm{~m}$. In North America, this may be related to the vertical distribution of the meridional moisture flux; the maximum is spread over a thick layer, whereas in the other sectors the peaks are closer to the surface (Jakobson and Vihma, 2010). The large spread in North America favours highly elevated humidity inversions that are generated by moisture advection instead of clear-sky radiative cooling of the surface. Further, the dependency between the occurrence of humidity inversions and sea level pressure was clearest at the Russian stations. A potential explanation is that in regions where the northward moisture advection is large, humidity inversions occur during both low- and high-pressure conditions, generated by different mechanisms. In Russia, however, the weaker moisture advection (Sorteberg and Walsh, 2008; Jakobson and Vihma, 2010), together with low nearsurface temperatures and deep and strong temperature inversions in winter, may explain the clearly highest humidity inversion occurrence under high-pressure conditions (Fig. 7a).

Although it is apparent that humidity inversions are very common and potentially an important part of the Arctic climate system, surprisingly few studies have so far addressed Arctic humidity inversions. Arctic temperature inversions have received much more attention during earlier decades (Kahl, 1990; Serreze et al., 1992; Kahl et al., 1996; Liu et al., 2006) as well as recently (Devasthale et al., 2010; Bintanja et al., 2011; Medeiros et al., 2011; Wetzel and Brümmer, 2011; Zhang et al., 2011), although their occurrence in the Arctic is even slightly lower compared to humidity inversions. Temperature inversions have been argued to have a remarkable 
negative feedback to the surface cooling efficiency (Bintanja et al., 2011), but impacts of Arctic humidity inversions on radiation as well as on atmospheric and surface temperatures have remained nearly unstudied. Based on the results of this study and a few existing earlier studies (Sedlar and Tjernström, 2009; Devasthale et al., 2011; Solomon et al., 2011; Sedlar et al., 2012; Tjernström et al., 2012) it is, however, justified to emphasize the great potential importance of humidity inversions in the Arctic climate system, especially for formation and maintenance of Arctic stratus clouds in wide spatial and temporal scales. Moisture provided by humidity inversions aloft seems vital to cloud processes, but exact mechanisms are currently not sufficiently understood, and particularly not parameterized in the state-of-art numerical models. The studies of Sedlar and Tjernström (2009) and Sedlar et al. (2012) demonstrated the role of humidity inversions on clouds based on data sets from a relatively short time period, but as we found that humidity inversions frequently occur on multiple levels, it seems probable that humidity inversions offer potential moisture sources aloft nearly all the time in the Arctic. This encourages further studies on humidity inversions and their interaction with clouds.

\section{Conclusions}

Humidity inversions are present nearly all the time in the Arctic atmosphere, likewise in the Antarctic. They occur in all circumpolar sectors and are typically found on multiple levels simultaneously. Our results showed that approximately half of the Arctic humidity inversions occurred at least partly within the same vertical layer with temperature inversions. The other half may, at least partially, be linked to the horizontal moisture transport, and its uneven vertical distribution in the Arctic. Humidity inversion occurrence was highest in the Arctic when the atmospheric surface pressure was high, similar to what was previously found for the Antarctic. Inversion properties did not show a particularly strong link with cloud cover in either of the polar areas. The most pronounced difference between the Arctic and Antarctic humidity inversions was the range of seasonal variability in inversion properties; in the Arctic, a clear seasonal cycle was detected in all inversion properties except for humidity inversion number in a profile and humidity inversion depth, whereas in the Antarctic the range of seasonal cycle was minor.

Humidity inversion statistics in the Arctic proved to be largely sensitive to the methodology applied. In particular, the statistics of the inversion strength, depth and base height for all inversions and the strongest inversions in a profile differed largely. Due to higher vertical resolution and different methodology, the radio-sounding-based water vapour profiles provide a humidity inversion climatology that deviates markedly from a satellite-based climatology, and, in particular, gives a different seasonal cycle of humidity inversions. Bearing this sensitivity to the methodology and resolution in mind, we strongly encourage further studies on humidity inversions due to their presumably vital, but so far poorly understood, role in cloud formation and maintenance in the Arctic.

Acknowledgements. We thank J. Sedlar and A. Solomon for their valuable comments on the discussion paper. This study was supported by the Academy of Finland through the CACSI and AMICO projects (contracts 259537 and 263918).

Edited by: T. Garrett

\section{References}

Andreas, E. L., Guest, P. S., Persson, P. O. G., Fairall, C. W., Horst, T. W., Moritz, R. E., and Semmer, S. R.: Nearsurface water vapour over polar sea ice is always near ice saturation, J. Geophys. Res., 107, SHE 8-1-SHE 8-15, doi:10.1029/2000JC000411, 2002.

Bintanja, R., Graversen, R. G., and Hazeleger, W.: Arctic winter warming amplified by the thermal inversion and consequent low infrared cooling to space, Nature, 4, 758-761, doi:10.1038/ngeo1285, 2011.

Devasthale, A., Willén, U., Karlsson, K.-G., and Jones, C. G.: Quantifying the clear-sky temperature inversion frequency and strength over the Arctic Ocean during summer and winter seasons from AIRS profiles, Atmos. Chem. Phys., 10, 5565-5572, doi:10.5194/acp-10-5565-2010, 2010.

Devasthale, A., Sedlar, J., and Tjernström, M.: Characteristics of water-vapour inversions observed over the Arctic by Atmospheric Infrared Sounder (AIRS) and radiosondes, Atmos. Chem. Phys., 11, 9813-9823, doi:10.5194/acp-11-9813-2011, 2011.

Durre, I., Russell, S. V., and Wuertz, D. B.: Overview of the Integrated Global Radiosonde Archive, J. Climate, 19, 53-68, 2006.

Durre, I. and Yin, X.: Enhanced Radiosonde Data For Studies of Vertical Structure, B. Am. Meteorol. Soc., 89, 1257-1262, doi:10.1175/2008bams2603.1, 2008.

Grachev, A. A., Uttal, T., Persson, P. O. G., Stone, R. S., Repina, I. A., Artamonov, A. Y., and Albee, R.: Boundary-layer measurements and surface fluxes in Arctic at the Eureka (Canada) and Tiksi (Russia) climate observatories, Geophys. Res., EGU General Assembly, Vienna, Austria, 22-27, 2012.

Jakobson, E. and Vihma, T.: Atmospheric moisture budget in the Arctic based on the ERA-40 reanalysis, Int. J. Climatol., 30, 2175-2194, doi:10.1002/joc.2039, 2010.

Jakobson, E., Vihma, T., Palo, T., Jakobson, L., Keernik, H., and Jaagus, J.: Validation of atmospheric reanalyses over the central Arctic Ocean, Geophys. Res. Lett., 39, L10802, doi:10.1029/2012GL051591, 2012.

Kahl, J. D.: Characteristics of the low-level temperature inversion along the Alaskan Arctic coast, Int. J. Climatol., 10, 537-548, 1990.

Kahl, J. D. W., Martinez, D. A., and Zaitseva, N. A.: Longterm variability in the low-level inversion layer over the Arctic Ocean, Int. J. Climatol., 16, 1297-1313, doi:10.1002/(sici)10970088(199611), 1996.

Kållberg, P., Berrisford, P., Hoskins, B., Simmmons, A., Uppala, S., Lamy-Thépaut, S., and Hine, R.: ERA-40 Atlas. Technical 
Report, ERA-40 Project Report Series, 19, 191 pp., ECWMF, Shinfield Park, Reading, UK, 2005.

Kilpeläinen, T., Vihma, T., Manninen, M., Sjöblom, A., Jakobson, E., Palo, T., and Maturilli, M.: Modelling the vertical structure of the atmospheric boundary layer over Arctic fjords in Svalbard, Q. J. Roy. Meteor. Soc., 138, 1867-1883, doi:10.1002/qj.1914, 2012.

Liu, Y. H., Key, J. R., Schweiger, A., and Francis, J.: Characteristics of satellite-derived clear-sky atmospheric temperature inversion strength in the Arctic, 1980-1996, J. Climate, 19, 4902-4913, doi:10.1175/jcli3915.1, 2006.

Mauritsen, T., Sedlar, J., Tjernström, M., Leck, C., Martin, M., Shupe, M., Sjogren, S., Sierau, B., Persson, P. O. G., Brooks, I. M., and Swietlicki, E.: An Arctic CCN-limited cloud-aerosol regime, Atmos. Chem. Phys., 11, 165-173, doi:10.5194/acp-11165-2011, 2011.

Medeiros, B., Deser, C., Tomas, R. A., and Kay, J. E.: Arctic Inversion Strength in Climate Models, J. Climate, 24, 4733-4740, doi:10.1175/2011jcli3968.1, 2011.

Nash, J., Smout, R., Oakley, T., Pathack, B., and Kurnosenko, S.: The WMO Intercomparison of Radiosonde Systems - Final Report Vacoas, Mauritius, 2-25 February 2005. Instruments and Observing Methods Report No. 83. WMO/TD-No. 1303, 2006.

Nash, J., Oakley, T., Vömel, H., and Wei, L.: The WMO Intercomparison of High Quality Radiosonde Systems Yangjiang, China, 12 July-3 August 2010, Instruments and Observing Methods Report No. 107. WMO/TD-No. 1580, 2011.

Nygård, T., Valkonen, T., and Vihma, T.: Antarctic LowTropospheric Humidity Inversions 10 yr Climatology, J. Climate, 26, 5205-5219, doi:10.1175/JCLI-D-12-00446.1, 2013.

Overland, J. E. and Turet, P.: Variability of the Atmospheric Energy Flux Across $70^{\circ} \mathrm{N}$ Computed from the GFDL Data Set, edited by: Johannessen, O. M, Muench, R. D., and Overland, J. E., The Polar Oceans and Their Role in Shaping the Global Environment, American Geophysical Union, 313-325, 1994.

Persson, P. O. G., Fairall, C. W., Andreas, E. L., Guest, P. S., and Perovich, D. K.: Measurements near the Atmospheric Surface Flux Group tower at SHEBA: Near-surface conditions and surface energy budget, J. Geophys. Res., 107, 8045, doi:10.1029/2000jc000705, 2002.

Rigor, I. G., Colony, R. L., and Martin, S.: Variations in Surface Air Temperature Observations in the Arctic, 1979-1997, J. Climate, 13, 896-914, 2000.

Sedlar, J. and Tjernström, M.: Stratiform Cloud-Inversion Characterization During the Arctic Melt Season, Bound.-Lay. Meterol., 132, 455-474, doi:10.1007/s10546-009-9407-1, 2009.

Sedlar, J., Shupe, M. D., and Tjernström, M.: On the Relationship between Thermodynamic Structure and Cloud Top, and its Climate Significance in the Arctic, J. Climate, 25, 2374-2393, doi:10.1175/jcli-d-11-00186.1, 2012.
Serreze, M. C., Kahl, J. D. W., and Schnell, R. C.: Low-level temperature inversions of the Eurasian Arctic and comparisons with Soviet drifting stations, J. Climate, 8, 719-731, 1992.

Serreze, M. C., Barry, R. G., and Walsh, J. E.: Atmospheric Water Vapor Characteristics at 70 N, J. Climate, 8, 719-731, 1995a.

Serreze, M. C., Rehder, M. C., Barry, R. G., Kahl, J. D. W., and Zaitseva, N. A.: The distribution and transport of atmospheric water vapour over the Arctic Basin, Int. J. Climatol., 15, 709727, 1995b.

Shupe, M. D., Persson, P. O. G., Brooks, I. M., Tjernström, M., Sedlar, J., Mauritsen, T., Sjogren, S., and Leck, C.: Cloud and boundary layer interactions over the Arctic sea ice in late summer, Atmos. Chem. Phys., 13, 9379-9399, doi:10.5194/acp-139379-2013, 2013.

Solomon, A., Shupe, M. D., Persson, P. O. G., and Morrison, H.: Moisture and dynamical interactions maintaining decoupled Arctic mixed-phase stratocumulus in the presence of a humidity inversion, Atmos. Chem. Phys., 11, 10127-10148, doi:10.5194/acp-11-10127-2011, 2011.

Sorteberg, A. and Walsh, J. E.: Seasonal cyclone variability at $70^{\circ} \mathrm{N}$ and its impact on moisture transport into the Arctic, Tellus A, 60, 570-586, doi:10.1111/j.1600-0870.2008.00314.x, 2008.

Tjernström, M., Leck, C., Persson, P. O. G., Jenssen, M. L., Oncley, S. P., and Targino, A.: The summertime Arctic atmosphere: Metorological measurements during the Arctic Ocean Experiment 2001, B. Am. Meteorol. Soc., 85, 1305-1321, doi:10.1175/BAMS-85-9-1305, 2004.

Tjernström, M., Birch, C. E., Brooks, I. M., Shupe, M. D., Persson, P. O. G., Sedlar, J., Mauritsen, T., Leck, C., Paatero, J., Szczodrak, M., and Wheeler, C. R.: Meteorological conditions in the central Arctic summer during the Arctic Summer Cloud Ocean Study (ASCOS), Atmos. Chem. Phys., 12, 6863-6889, doi:10.5194/acp-12-6863-2012, 2012.

Wetzel, C. and Brümmer, B.: An Arctic inversion climatology based on the European Centre Reanalysis ERA-40, Meteorol. Z., 20, 589-600, doi:10.1127/0941-2948/2011/0295, 2011.

Vihma, T., Kilpeläinen, T., Manninen, M., Sjöblom, A., Jakobson, E., Palo, T., Jaagus, J., and Maturilli, M.: Characteristics of Temperature and Humidity Inversions and Low-Level Jets over Svalbard Fjords in Spring, Adv. Meteorol., 2011, 486807, doi:10.1155/2011/486807, 2011.

Zhang, Y., Seidel, D. J., Golaz, J. C., Deser, C., and Tomas, R. A.: Climatological characteristics of Arctic and Antarctic Surface-Based Inversions, J. Climate, 24, 5167-5186, doi:10.1175/2011JCLI4004.1, 2011. 